\title{
Assessing Factors Contributing to Erratic Water Supply in Peri Urban Areas. A Case Study of Chazanga Compound in Lusaka
}

\author{
Reuben Lazarus Zulu ${ }^{1 *}$, Emmanuel Kooma ${ }^{2}$ \\ ${ }^{1}$ Department of Public Health, Texila American University, Lusaka, Zambia \\ ${ }^{2}$ Ministry of Health, National Malaria Elimination Centre, Lusaka, Zambia
}

\begin{abstract}
According to World Health Organisation, one person needs 20 litres of water per day for physiological and domestic purposes. However, in some places people received little or no water at all. This was the case of Chazanga compound where some households experienced erratic water supply daily. Erratic water supply resulted in people drawing water from shallow wells which were usually contaminated. Consumption of contaminated water led to diarrhoeal diseases. This prompted for research to be conducted in Chazanga compound. The main objective was to establish the factors contributing to erratic water supply in Chazanga compound. A questionnaire was administered to 397 households. The generated data was analyzed using the Statistical Package for the Social Sciences. The results revealed that the problem of erratic water supply was real in Chazanga Compound. The other factors were poor management by the water supplier, high demand due to population growth and high cost of water. Erratic water supply in Chazanga made residents resort to drawing water from shallow wells, resulting in the increase in diarrhoea cases. The study further revealed that to avert the erratic water supply, the supplier needed to repair all leaking water distribution pipes, sink more boreholes and erect a bigger water reservoir. The other recommendations were to fit bigger distribution pipes, construct more communal taps, and improve the management of water supply by the water suppliers. The purpose of this research was to have an improved supply of safe and adequate water in Chazanga compound.
\end{abstract}

Keywords: Chazanga, Contributing, Erratic, Factors, Peri-urban and Water Supply.

\section{Introduction}

The Millennium Development Goals Report indicated that 783 million people or 11 percent of the global population remained without access to an improved source of drinking water. Such sources included household connections, public standpipes, boreholes, protected dug wells, protected springs and rainwater collections. Furthermore, there were regions particularly affected such as the Sub-Saharan Africa where over $40 \%$ of all people without improved drinking water lived.

The United Nations had been addressing the global crisis caused by insufficient water supply to satisfy basic human needs and growing demands of the world's water resources to meet human, commercial, and agricultural needs. The United Nations Water Conference, the International Drinking Water Supply and Sanitation Decade, the International Conference on Water and the Environment and the Earth
Summit all focused on water supply [1]. This led to the establishment of the World Water Day which falls on $22^{\text {nd }}$ March. Every year on $22^{\text {nd }}$ March, the World commemorates the World Water Day, in order to emphasize on the importance of conserving and proper management of this vital resource. It also focuses on improving access to adequate, clean and safe drinking water.

Everyday millions of people in Africa, usually women and girls, walked long distances to have access to any water. The length of time it took to collect the little water they can get meant that they did not have time to do anything else during the day. In some countries, children did not get the chance to go to school simply because they were too busy collecting water. In some instances, water was rationed by the Water Utility Companies. Thus, limiting access to adequate and safe water to the people [2].

Zambia has had its share of the water supply challenges. In Zambia, more than one third of the 
population did not have access to clean water and more than half lacked access to proper sanitation facilities. Water and sanitation facilities in basic schools were generally poor. The Government's Educational Statistical Bulletin of 2004 indicated that more than 25 percent of basic schools did not have access to a safe water supply (borehole-piped, boreholepump, piped water, or protected well) and improved sanitation facilities. Not having access to clean and safe water led to diseases like diarrhea and cholera, among others [3].

Water, sanitation, and hygiene factors were responsible for over 24000 deaths in 2004, which accounted for 11.4 percent of all deaths in Zambia. In 1991, Zambia's water sector reforms prioritized the actions on improving domestic water supply and sanitation accessibility due to its impact on the population's health. The targets that were set to meet the MDG goals also influenced the investment [4]. UNICEF has been supporting the Government of the Republic of Zambia to achieve MDGs 7 and 10 to halve the proportion of people without sustainable access to safe drinking water and basic sanitation by 2015. The most affected by problems of water were peri urban and rural areas of Zambia. This led to the initiation of National Rural Water and Sanitation Programs in all rural and peri-urban districts in order to address the water and sanitation challenges [3]. One such area affected by water problems was Chazanga compound of Lusaka district in Zambia.

Chazanga compound had been experiencing erratic water supply for more than seven months. An average of 300 households either received as little as 20 litres per household or no water at all on a daily basis. This was against the World Health Organisation's recommendation of the minimum requirement of 20 litres of water per person in a day for physiological and domestic use [5]. The erratic water supply in Chazanga compound forced many households to draw water from the shallow wells which were located near the pit latrines. The erratic water supply contributed to a lot of diseases such as water washed and water-borne diseases.

The water borne diseases that arose from erratic water supply were cholera, typhoid, dysentery and other common diarrhoeas. The consumption of water from shallow wells as a result of erratic water supply contributed to the high incidence of diarrhoea cases in Chazanga [6].

The lack or inadequate water supply also contributed to poor hygiene practices where people were rationing of the little water resulted in not bathing, washing of clothes and not washing the hands after use of the toilet.

The other problems due to the erratic water supply in Chazanga compound were trachoma and pediculosis due to lice infestation. These diseases came as a result of an inadequate supply of water [7].

The Health Management Information System Outpatient registers at Chazanga Health Centre showed that among the top ten diseases were diarrhoea, digestive system and non-infectious skin cases [8] as shown in table 1 .

This prompted the researcher to look into the factors contributing to erratic water supply in Chazanga compound of Lusaka.

Chazanga Water Trust erected communal water points in the community for people to access clean and safe water. However, they were not adequate to cater for the growing population.

The solutions to erratic water supply were for the water supplier needed to repair all leaking water distribution pipes, sink more boreholes, erect a bigger water reservoir tanks, fit bigger distribution pipes, construct more communal taps and improve the management of water supply.

The purpose of the study was to establish the factors that contributed to the problem of erratic water supply and come up with interventions to address the causes of erratic water supply in order to improved supply of safe and adequate water in Chazanga compound and prevent the water-borne and water washed diseases.

The general objective of the research was to establish the factors contributing to erratic water supply in Chazanga compound.

The main limitations to this research were inadequate time and funds to carry out the research. 
Table 1. Top 10 Diseases at Chazanga Clinic (Source: Lusaka DHO HMIS)

\begin{tabular}{|l|l|l|}
\hline SN & Diseases & Number of Cases \\
\hline 1 & Respiratory Infection: non-pneumonia & 1158 \\
\hline 2 & Diarrhoea (non-bloody) & 585 \\
\hline 3 & Muscular skeletal and connective tissue (not trauma) & 258 \\
\hline 4 & Digestive system: (not infectious) & 250 \\
\hline 5 & Pyrexia of Unknown Origin (PUO) & 239 \\
\hline 6 & Clinical case of malaria & 197 \\
\hline 7 & Nervous System Disorders: Other & 190 \\
\hline 8 & Trauma: Other Injuries, wounds & 186 \\
\hline 9 & Throat Diseases & 161 \\
\hline 10 & Skin Diseases (not infectious) & 111 \\
\hline
\end{tabular}

\section{Materials and Methods}

The research was conducted in Chazanga compound. Chazanga compound was located approximately ten kilometres on the northern part of Lusaka City, bordering Chisamba district. On the southern side, it bordered Chipata compound with old Kabanana and Chipwalu village on the eastern side. On the western side was Lilanda village of Chisamba district.

Chazanga compound had a population of 38,601 people with 8,000 households. The majority of the population were youths. The compound was made up of two villages namely Lilanda and Chipwalu villages. The headmen were responsible for land allocation and arbitration over the traditional and cultural matters. The target population were the households, water providers or suppliers and organisations of Chazanga compound that drew water from the Chazanga Water Trust communal and individual taps for their domestic uses.

The economic activities of the residents were farming, trading in various commodities as well as government and private companies' employees. Sixty percent of the residents own small businesses such as shops, groceries, bars, clubs and market stalls while 35 percent were either employees in the government or private institutions. The remaining five percent were subsistence farmers.

The compound had one government health centre (Chazanga clinic) and one private health facility called Bwafwano Integrated Health Services. However, there were other unregistered private clinics which offer health services to the public in Chazanga compound.

The sample size for this research was two percent of the total households which was 397 households. 300 respondents came from Chazanga compound, while from Lilanda villages 97 respondents were selected. The sample was not very big because the population had similar characteristics and experienced the same water problem, hence no need for a bigger sample. The formula used to determine the sample size was:

$$
\mathrm{n}=\frac{\mathrm{N}}{1+\mathrm{N}(\overline{\mathrm{e}})^{2}}
$$

To ensure that each unit of the sample had an equal chance of being included in the study to avoid biases, systematic random sampling was used in sampling. This involved the selection of sample units at regular intervals. The systematic random sampling procedure was employed. The sampling interval was 25 , which meant samples were collected every after the 25th household. This was done as the research was going on using the research assistants. In order to ensure accuracy in data collected, a ninety-five percent confidence level was applied.

In this study, both qualitative and quantitative methods of data collection were employed. This helped to maximize information and quality of data collected to reduce the possibilities of any biases. The data collection tools used were field observations and structured interviews using the questionnaires. The main data collection tool was the questionnaire. This was done through structured interviews of the respondents.

After collection, the data was then analyzed using Microsoft Excel program for the generation of charts and Scientific Package for Social Sciences (SPSS) to come up with the frequency tables. 


\section{Results}

Chazanga compound had been experiencing erratic water supply for some time. An average of 300 households either received as little as 20 litres per household or no water at all on a daily basis. This was against the World Health Organisation's recommendation of the minimum requirement of 20 litres of water per person in a day for physiological and domestic use [5].

The inadequate water supply to majority of residents of Chazanga compound led to many health problems and concerns which included people being forced to draw water from shallow wells which were unsafe resulting in waterborne diseases such as cholera, typhoid, dysentery, amoebiasis, ascariasis, rotavirus diarrhoea, poliomyelitis and shigellosis.

The research was conducted to assess the factors that contributed to erratic water supply. The data was analysed the following results were obtained in relation to erratic water supply in Chazanga compound.

The demographic characteristics of the respondents showed that the majority of the respondents were in the age group 30-34 which represented of 16.4 percent and the minority were in the age group 80-84 with 0.3 percent. The results further indicate that from the total of 397 sampled respondents, the majority of them were females representing 79.3 percent, while the males were represented by the remaining 20.7 percent.

The marital status showed the married as the majority, which were represented 63.4 percent of the total 397 respondents. This was followed by 21.4 percent of the respondents that were single. Thirdly, 10.6 percent of the respondents indicated that they were widowed and amongst the respondent's 2.8 percent were separated. Lastly, the minority 1.8 percent were divorced. This is summarised in table 2 .

Many of the respondents in the sample had a male adult as the head of the household $(81.8$ percent) followed by the female-headed households with 17.9 percent and the least household being headed by a child at 0.3 percent.

The provision of an adequate amount of water to the people and where the water was drawn was essential to the wellbeing of humans. Water was supposed to be supplied in adequate amounts and also the place where it was being drawn or tapped should be safe for use. Table 3 shows the percent distribution of the various sources of water for domestic use in Chazanga compound. The results then indicate that most of the respondents drew water from communal taps with 83.9 percent followed by other sources of water other than those listed in the study with 13.9 percent. The least sources of water for domestic use were shallow wells, boreholes and rivers with $1.3,0.8$ and 0.3 percent respectively.

The average water use for drinking, cooking and personal hygiene in any household should be atleast 20 litres per person per day as recommended by World Health Organisation. The results in Table 4 show that most of the respondents used 60 litres of water per day, followed by households who used 100 litres of water per day with 42.3 percent. The rest of the households used 200 litres, 20 litres and above 200 litres represented by 5.8 percent, 4.3 percent and 3.5 percent respectively.

On the other hand, the results, as shown in table 5, revealed that many of the respondents representing 40.8 percent drew 100 litres of water from the source per day. This was followed by the respondents who drew 60 litres of water with 28 percent and thirdly respondents who drew 200 litres of water. The minority of the respondents said they drew above 200 litres of water from the source representing 6.3 percent.

The respondents were asked if there were times that they had experienced erratic water supply in the compound and the result are shown in figure 1 that of the sample of 397, 394 respondents representing 99 percent had experienced erratic water supply while the minority of 4 respondents representing 1 percent had not experienced erratic water supply. The results further showed that respondents drew water from other sources such as shallow wells, streams and boreholes when they experience erratic water supply as shown in table 6 .

Table 6 reveals that from the respondents who had experienced erratic water supply, the majority got water from a shallow well representing 76.8 percent followed by water drawn from boreholes with 17 percent. Thirdly, respondents asked their neighbours if they could draw water from their home, which was represented by 4.1 percent and water from other sources other than the ones mentioned in the research with 1.3 percent. The minority got water from a river/stream with 0.3 percent. 
Erratic water supply could lead to many health problems and concerns. Among the many diseases that could break out due to erratic water supply, Diarrhoea, Cholera, Cough, Eye problems, Typhoid fever and Malaria were the responses of the respondents. As indicated in table 7, the majority said that diarrhoea with 49.4 percent would likely come due to erratic water supply followed by cholera with 17.9 percent. Other respondents said a combination of cholera and diarrhoea would breakout which was represented by 15.4 percent. Fourthly, respondents said malaria would come due to inadequate water supply with 10.6 percent followed by typhoid fever represented by 4.8 percent, then eye problems and coughing both having 0.5 percent. However, one percent of the respondents said that they did not know what diseases came due to inadequate water supply.

The research revealed that there were varied reasons of why there was an inadequate supply of water in Chazanga compound. The respondents revealed the various factors contributing to the erratic supply of water in the compound which include few boreholes, high demand of water by a growing population, highland hence no water due to low pressure, poor planning of the compound and hence water shortages, leakages in the pipes, small water distribution pipes, high cost of water, few communal taps, load shading which affects supply of water, negligence by government, few tanks and poor management by water suppliers. The rest of the respondents did not know the cause of erratic water supply. The respondents said having a few tanks caused erratic water supply at 34.3 percent followed load shading at 17.8 percent and few boreholes at $10.1 \%$ then few communal taps with $8.6 \%$. The rest of the respondents said the high demand for water by a growing population at $8.3 \%$, poor water management from suppliers, leakages in water distribution pipes, and small water distribution pipes, at $8.3 \%, 7.6 \%, 7.5 \%$ and $2.7 \%$, respectively.

The minority of the respondents said the land was too high hence no water due to low pressure, water was costly and negligence by government at $1.3 \%, 0.5 \%$ and $0.3 \%$, respectively. On the other hand, $1 \%$ of the respondents did not have any knowledge of what causes the erratic water supply in the compound.
The lack of adequate boreholes in an area such as Chazanga could be useful in explaining what contributed to the inadequate supply of water to the area. The respondents represented by $35 \%$ strongly agreed that the number of boreholes affects the water supply to the compound, followed by the respondents who disagreed at $34 \%$ and $29.7 \%$ who agreed. The minority of the respondents strongly disagreed with $1.3 \%$.

The respondents were further asked if the daily yield from boreholes affects the amount of water supplied to the compound. The results to the question are shown in figure 3 indicating that the majority of the respondents strongly agreed that the daily yield from boreholes affects the amount of water supplied to Chazanga representing $36 \%$. This was followed by respondents who agreed at $31.7 \%$ and those that disagreed at $30.4 \%$; whereas $2 \%$ of the respondents strongly disagreed.

The respondents were also asked if the leakages in the water distribution pipes affected the amount of water supplied to the people. Overall, figure 4 shows that the majority of the respondents $(69.3 \%)$ strongly agreed that leakages in the water distribution pipes affected the water supplied to people. $26.2 \%$ of the respondents agreed to this while the minority disagreed and strongly disagreed both representing $2.3 \%$.

The size of water reservoirs and the amount of stored water should be able to meet the high demand for water during periods of erratic water supply. The respondents where then asked if the size of the water reservoirs affects the amount of water stored in order to meet the demand for water during the peak periods. Figure 5 graphically represented the results to the question that slightly over half of the respondents strongly agreed that the size of the water reservoirs affects the amount of water stored in order to meet the water demand during the peak periods. This was followed by $38 \%$ of the respondents who agreed to this and $9 \%$ who disagreed to this question while only $1 \%$ of the respondents strongly disagreed.

The erratic water supply that had been experienced in Chazanga compound for the past months called for immediate improvements to increase access to safe and adequate water supply to the population. When asked on what should be done to improve the supply of water to 
the compound, respondents gave various recommendations which include; Sink more boreholes, repair the leakages in the distribution pipes, erect more water tanks, fit bigger distribution pipes, construct more communal taps, find an alternative source of power for the submersible water pumps and improve the management of water supply by the water suppliers. Table 9 shows the \% distribution of the possible interventions to improve the supply of water in Chazanga compound.

Table 9 reveals that most of the respondents recommended that more water tanks should be erected $(47.1 \%)$. This was followed by the respondents who recommended the sinking of more boreholes $(21.2 \%)$ and construction of more communal taps at $16.6 \%$. Fitting bigger water distribution pipes and improving management of water by the distributors were also recommended, both representing $5.3 \%$. The minority suggested the repair of leakages in the water pipes and finding an alternative source of power for the water pumps at $2.8 \%$ and $1.7 \%$ respectively.

The factors contributing to erratic water supply played a part in the inadequate and safe supply of water. This section looked at the relationship between the people who experienced erratic water supply and the factors that contributing to inadequate water supply. Table 10 shows the relationship between respondents who experienced erratic water supply and the factors contributing to the problem.

It shows that the number of available boreholes was not statistically related to the erratic water supply in Chazanga compound. All the respondents who had experienced erratic water supply strongly disagreed that the number of boreholes did not contribute to the erratic water supply. The table also shows that there was no statistical relationship between the daily water yield from boreholes and the erratic supply of water.

Leakages from water distribution pipes was significantly related to the erratic supply of water at $\mathrm{P}<0.05$. Almost all the respondents strongly agreed (99.3\%) that leakages from water distribution pipes contributed to inadequate water supply to the compound.

Table 10 further shows that the size of the water reservoirs and the erratic water supply to the compound was not statistically significant.

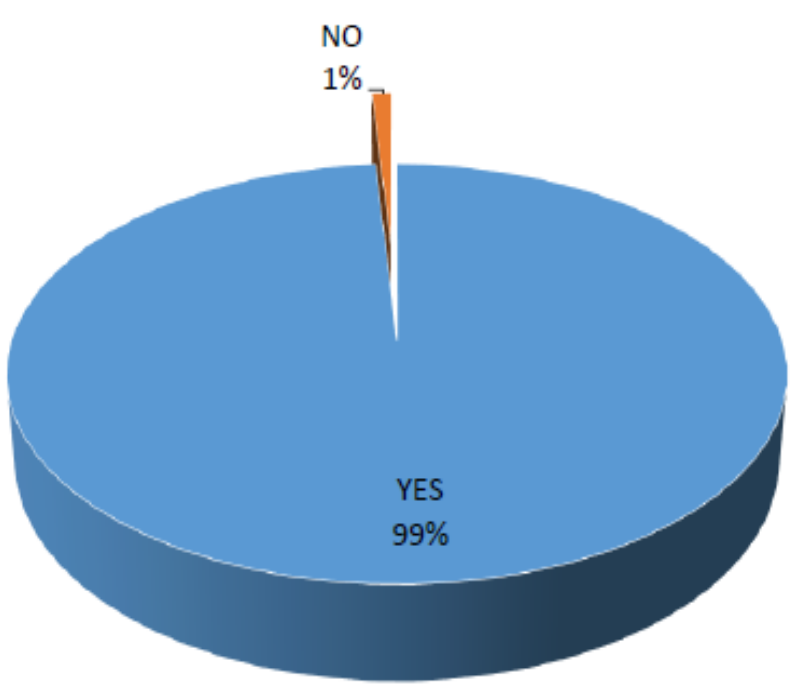

Figure 1. Percent Distribution of Whether Respondents had Experienced Erratic Water Supply 


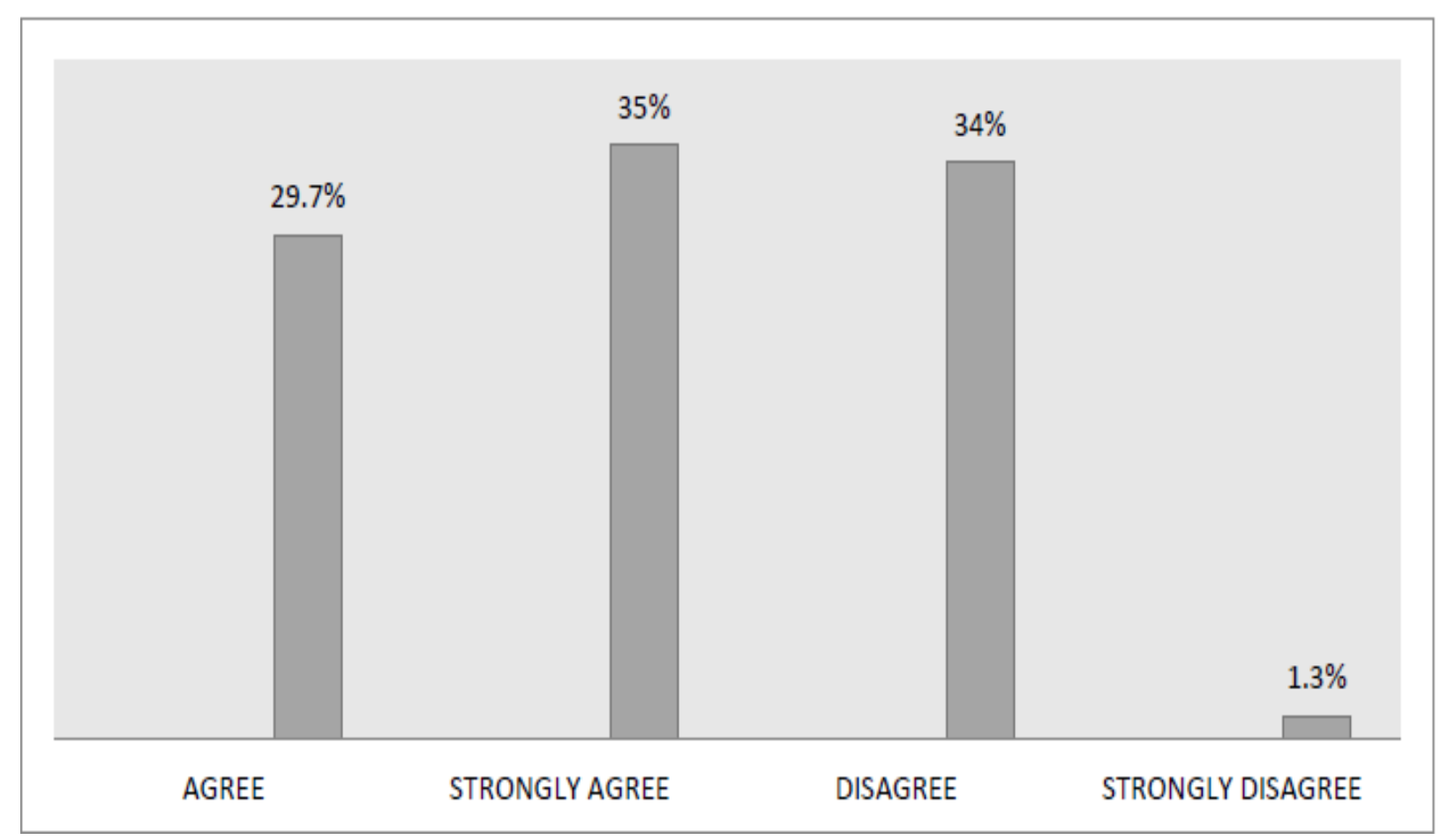

Figure2. Percent Distribution of Whether the Number of Boreholes Affected the Amount of Water Supply

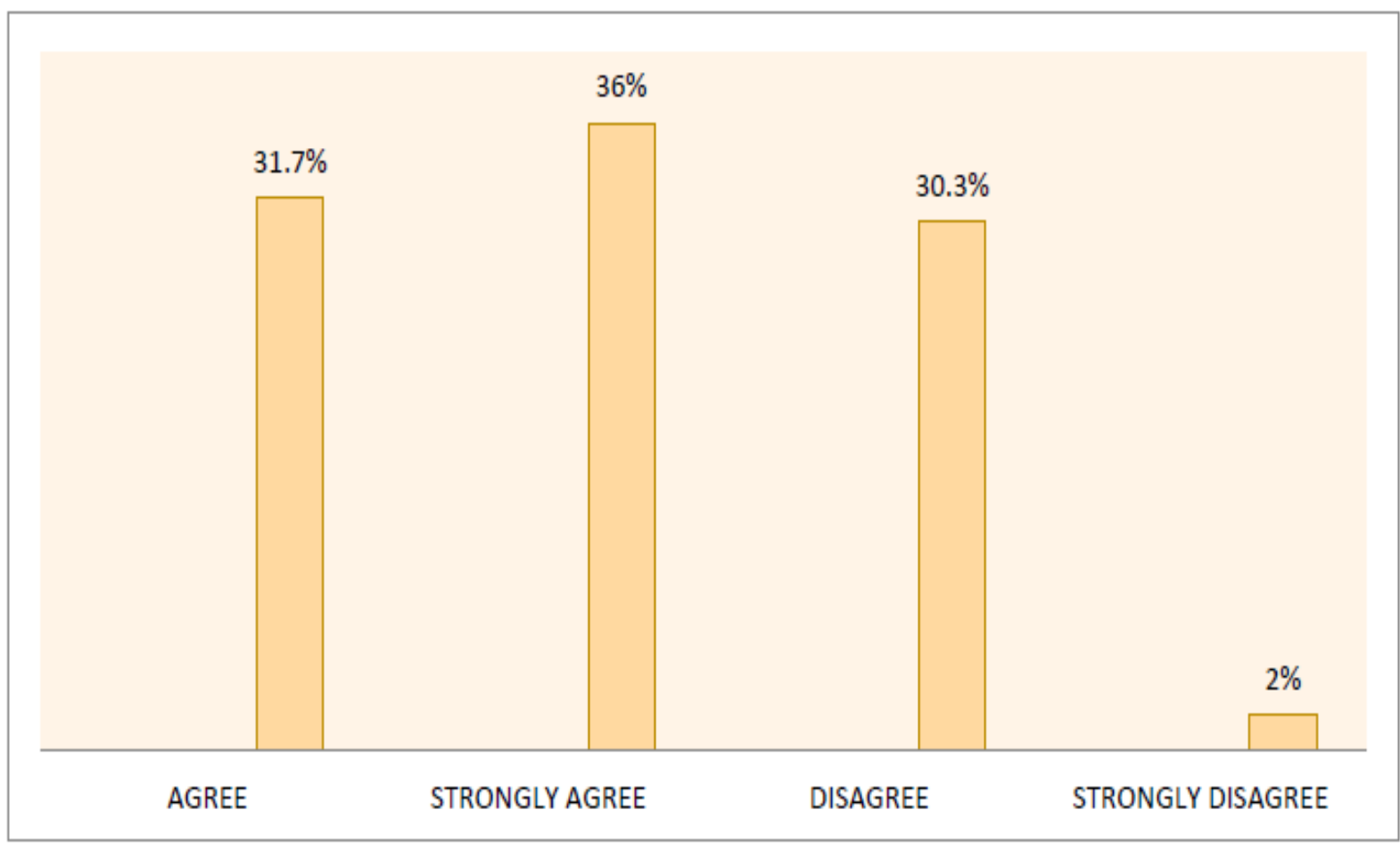

Figure 3. Percent Distribution of Whether the Daily Yield from Boreholes Affected the Amount of Water Supply 


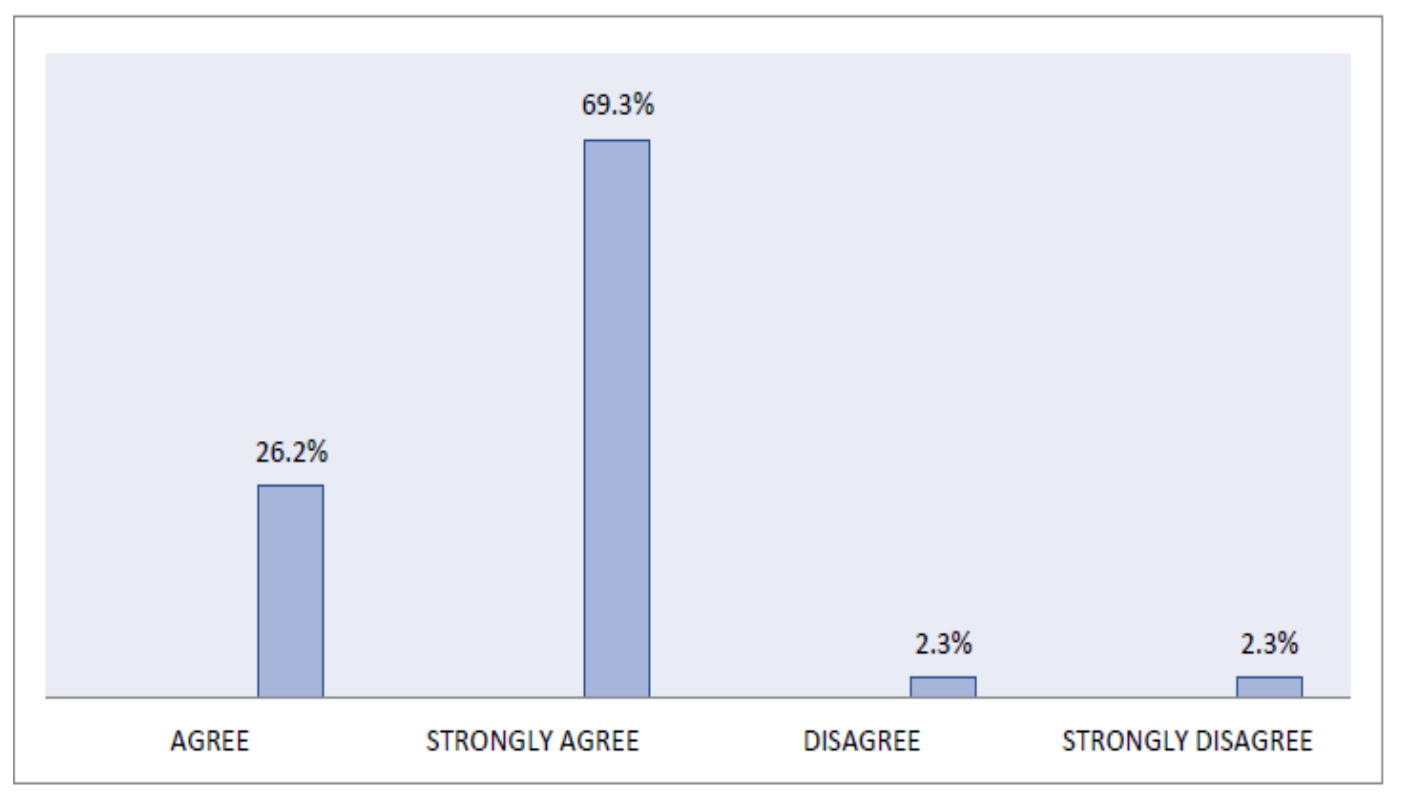

Figure 4. Percent Distribution of Whether the Leakages in the Distribution Pipes Affected the Water Supply

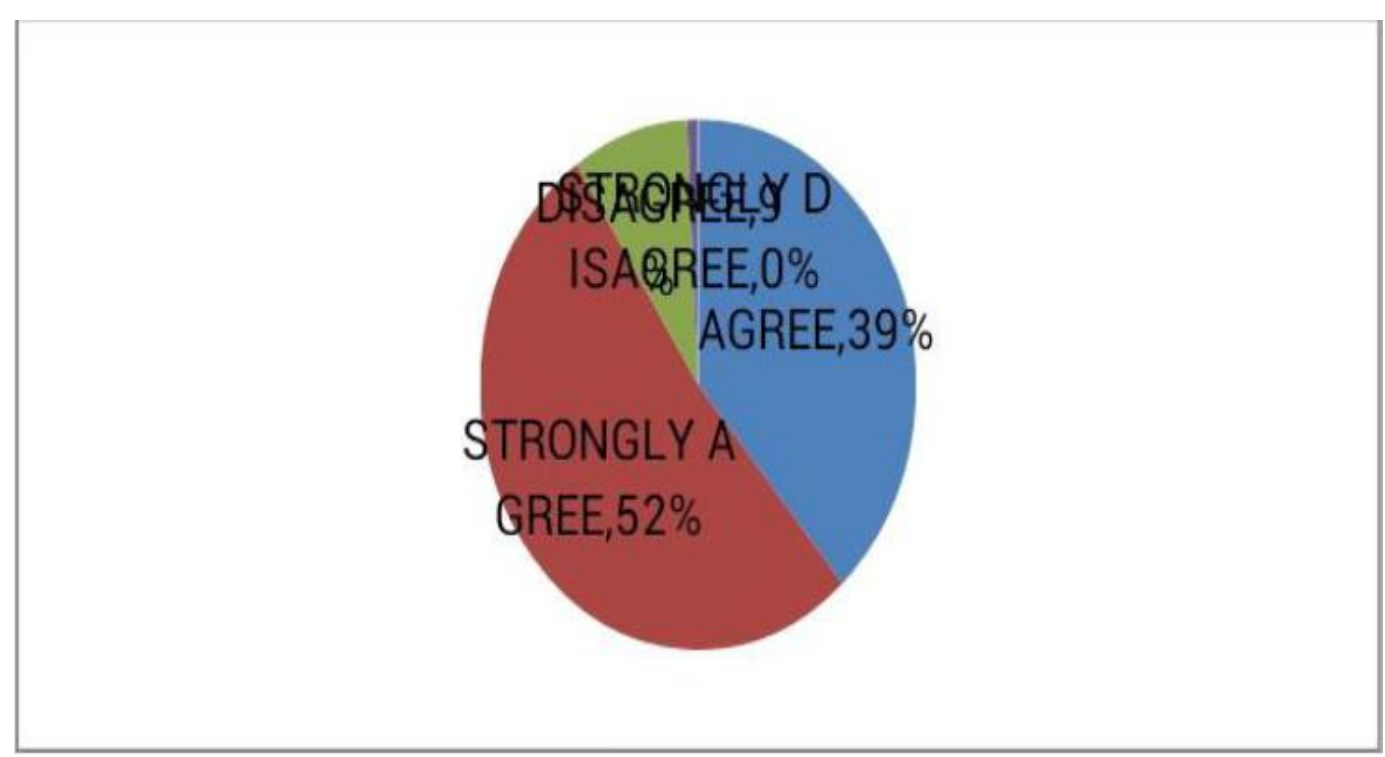

Figure 5. Percent Distribution of Whether Size of the Water Reservoirs Affected the Amount of Water Stored in Order to Meet the Demand During the Peak Periods

Table 2. Percent Distribution of Demographic Characteristics of Respondents

\begin{tabular}{|l|l|l|}
\hline Characteristics & Count & Percent \\
\hline Age Group & \multicolumn{2}{|l|}{} \\
\hline $15-19$ & 46 & 11.6 \\
\hline $20-24$ & 59 & 14.9 \\
\hline $25-29$ & 54 & 13.6 \\
\hline $30-34$ & 65 & 16.4 \\
\hline $35-39$ & 47 & 11.8 \\
\hline $40-44$ & 36 & 9.1 \\
\hline $45-49$ & 24 & 6 \\
\hline $50-54$ & 15 & 3.8 \\
\hline $55-59$ & 9 & 2.3 \\
\hline $60-64$ & 22 & 5.5 \\
\hline $65-69$ & 9 & 2.3 \\
\hline
\end{tabular}




\begin{tabular}{|l|l|l|}
\hline $70-74$ & 9 & 2.3 \\
\hline $75-79$ & 1 & 0.3 \\
\hline $80-84$ & 1 & 0.3 \\
\hline Sex & \multicolumn{3}{|l|}{} \\
\hline Male & 82 & 20.7 \\
\hline Female & 315 & 79.3 \\
\hline Marital Status \\
\hline Single & 85 & 21.4 \\
\hline Married & 252 & 63.4 \\
\hline Separated & 11 & 2.8 \\
\hline Divorced & 7 & 1.8 \\
\hline Widowed & 42 & 10.6 \\
\hline Head of Household \\
\hline Male Adult & 325 & 81.8 \\
\hline Female Adult & 71 & 17.9 \\
\hline Child headed & 1 & 0.3 \\
\hline Total & $\mathbf{3 9 7}$ & $\mathbf{1 0 0}$ \\
\hline
\end{tabular}

Table 3. Percent Distribution of Sources of Water for Domestic use in Chazanga

\begin{tabular}{|l|l|l|}
\hline Source & Count & Percent \\
\hline Communal tap & 333 & 83.9 \\
\hline River/stream & 1 & 0.3 \\
\hline Shallow well & 5 & 1.3 \\
\hline Borehole & 3 & 0.8 \\
\hline Other & 55 & 13.9 \\
\hline Total & $\mathbf{3 9 7}$ & $\mathbf{1 0 0}$ \\
\hline
\end{tabular}

Table 4. Percent Distribution of Litres of Water used in a Day by Households

\begin{tabular}{|l|l|l|}
\hline Litres & Count & Percent \\
\hline 20 & 17 & 4.3 \\
\hline 60 & 175 & 44.1 \\
\hline 100 & 168 & 42.3 \\
\hline 200 & 23 & 5.8 \\
\hline Above 200 & 14 & 3.5 \\
\hline Total & $\mathbf{3 9 7}$ & $\mathbf{1 0 0}$ \\
\hline
\end{tabular}

Table 5. Percent Distribution of Litres of Water Drawn from the Source per Day by Respondents

\begin{tabular}{|l|l|l|}
\hline Litres & Count & Percent \\
\hline 20 & 26 & 6.5 \\
\hline 60 & 111 & 28 \\
\hline 100 & 162 & 40.8 \\
\hline 200 & 73 & 18.4 \\
\hline Above 200 & 25 & 6.3 \\
\hline Total & $\mathbf{3 9 7}$ & $\mathbf{1 0 0}$ \\
\hline
\end{tabular}


Table 6. Percent Distribution of where the Respondents Drew Water from if they Experienced Erratic Water Supply

\begin{tabular}{|l|l|l|}
\hline Water Source & Count & Percent \\
\hline River/stream & 3 & 0.8 \\
\hline Shallow well & 302 & 76.8 \\
\hline Borehole & 67 & 17 \\
\hline Ask from neighbours & 16 & 4.1 \\
\hline Other & 5 & 1.3 \\
\hline Total & $\mathbf{3 9 4}$ & $\mathbf{1 0 0}$ \\
\hline
\end{tabular}

Table 7. Percent Distribution of Diseases that Could Come due to Erratic Water Supply

\begin{tabular}{|l|l|l|}
\hline Diseases & Count & Percent \\
\hline Diarrhoea & 196 & 49.4 \\
\hline Cholera & 71 & 17.9 \\
\hline Malaria & 42 & 10.6 \\
\hline Coughing & 2 & 0.5 \\
\hline Eye problems & 2 & 0.5 \\
\hline Typhoid & 19 & 4.8 \\
\hline Cholera and Diarrhoea & 61 & 15.4 \\
\hline Don't know & 4 & 1 \\
\hline Total & $\mathbf{3 9 7}$ & $\mathbf{1 0 0}$ \\
\hline
\end{tabular}

Table 8. Percent Distribution of the Likely Causes of Erratic Water Supply in Chazanga Compound

\begin{tabular}{|l|l|l|}
\hline Causes of Erratic Water Supply & Count & Percent \\
\hline Few boreholes & 40 & 10.1 \\
\hline High demand for water by a growing population & 33 & 8.3 \\
\hline The land is high hence no water due to low pressure & 5 & 1.3 \\
\hline Leakages in pipes & 30 & 7.5 \\
\hline Small water distribution pipes & 11 & 2.7 \\
\hline Water is costly & 2 & 0.5 \\
\hline Few communal taps & 34 & 8.6 \\
\hline Load shading affects water supply & 71 & 17.8 \\
\hline Negligence by government & 1 & 0.3 \\
\hline Few tanks & 136 & 34.3 \\
\hline Poor management by water suppliers & 30 & 7.6 \\
\hline Don't know & 4 & 1 \\
\hline Total & $\mathbf{3 9 7}$ & $\mathbf{1 0 0}$ \\
\hline
\end{tabular}

Table 9. Percent Distribution of What Should be Done to Improve the Water Supply in Chazanga.

\begin{tabular}{|l|l|l|}
\hline Possible Interventions & Count & Percent \\
\hline Sink more boreholes & 84 & 21.2 \\
\hline Repair the leakages in the water pipes & 11 & 2.8 \\
\hline Erect more water tanks & 187 & 47.1 \\
\hline Put bigger water distribution pipes & 21 & 5.3 \\
\hline Construct more communal taps & 66 & 16.6 \\
\hline $\begin{array}{l}\text { Find alternative source of power for } \\
\text { water pumps }\end{array}$ & 7 & 1.7 \\
\hline $\begin{array}{l}\text { Improve management by water } \\
\text { distributors }\end{array}$ & 21 & 5.3 \\
\hline Total & $\mathbf{3 9 7}$ & $\mathbf{1 0 0}$ \\
\hline
\end{tabular}


Table 10. Respondents who Experienced Erratic Water Supply and the Factors Contributing to Erratic Water Supply

\begin{tabular}{|l|l|l|l|l|l|}
\hline \multirow{2}{*}{ Factors } & \multicolumn{3}{l}{ Erratic Water Supply (N=397) } \\
\cline { 2 - 5 } & Yes & No & \multicolumn{2}{l|}{ sig (2 sided) } \\
\hline Number of Boreholes & $99.2 \%$ & $0.8 \%$ & & \\
\hline Agree & $99.3 \%$ & $0.7 \%$ & 0.919 & \\
\hline Strongly Agree & $98.5 \%$ & $1.5 \%$ & & \\
\hline Disagree & $100 \%$ & $0 \%$ & & \\
\hline Strongly Disagree & $98.4 \%$ & $1.6 \%$ & & \\
\hline Daily Yield from Boreholes & $99.3 \%$ & $0.7 \%$ & 0.878 & \\
\hline Agree & $99.2 \%$ & $0.8 \%$ & & \\
\hline Strongly Agree & $100 \%$ & $0 \%$ & & \\
\hline Disagree & $99.0 \%$ & $1 \%$ & & \\
\hline Strongly Disagree & $99.3 \%$ & $0.7 \%$ & 0.023 & $*$ \\
\hline Leakages from Pipes & $88.9 \%$ & $11.1 \%$ & & \\
\hline Agree & $99.0 \%$ & $1 \%$ & & \\
\hline Strongly Agree & & \multicolumn{2}{|l|}{} \\
\hline Disagree & $98.0 \%$ & $2 \%$ & & \\
\hline Strongly Disagree & $99.5 \%$ & $0.5 \%$ & 0.505 & \\
\hline Size of Water Reservoirs & $100 \%$ & $0 \%$ & & \\
\hline Agree & $100 \%$ & $0 \%$ & & \\
\hline Strongly Agree & &
\end{tabular}

$P$-value in parenthesis $* p<0.05$

\section{Discussion}

This research aimed to identify the factors contributing to the erratic water supply in Chazanga compound. The research identified factors affecting the supply of water to the compound. This section discusses the findings.

The Millennium Development Goals (MDG's) were agreed upon by the international community in 2000 with access to safe drinking water as one of the 18 objectives. By and large it had shown that water played a critical role in achieving all the MDG's and thus placing it at the centre. In Zambia, though significant progress was reported, achievement of the MDGs by 2015, particularly in Rural and PeriUrban areas was unlikely [9].

Environmental Council of Zambia, states that [10] increase in the population of Zambia especially in urban areas led to problems of accessing sufficient clean water supply. Lusaka province had an approximate population of over 3 million, which was mainly concentrated in the unplanned settlements or peri-urban areas (11). This increase in population in peri-urban areas like Chazanga compound led to increased demand for water supply, thereby introducing serious shortages which were further associated with adverse effects.

The research showed that there were varied reasons of why there was an inadequate supply of water in Chazanga compound. Overall, of all the sample of 397, 99 percent had experienced erratic water supply, while only 1 percent had not experienced erratic water supply over the past few months. The research also showed that most of the respondents drew water from communal taps, followed by other sources of water such their own taps, their neighbours' taps. The least sources of water for domestic use are shallow wells, boreholes, and rivers.

The research further reveals that most of the respondents used about 60 litres of water per day, followed by households who used about 100 litres of water. The minority of the households used about 200 litres, 20 litres and above 200 litres per day, respectively. This showed that the WHO recommended average water use for drinking, cooking and personal hygiene in any household of at least 20 litres per person per day was not being observed. Many of the respondents drew about 100 litres of water 
from the source per day, and the minority of the respondents said they drew above 200 litres of water from the source.

The respondents who had experienced erratic water supply were then further asked where they drew water. From the respondents who had experienced erratic water supply, the majority got water from a shallow well followed by water drawn from boreholes. Thirdly, respondents asked their neighbours if they could draw water from their home and water from other sources such as a nearby clinic. The minority got water from a river/stream.

Water quality and quantity was an important component to health. For instance, water-borne diseases like cholera spread very fast and affected many parts of the country [10]. The research showed that respondents said that diseases that would come due to lack of inadequate water in order of responses were diarrhoea, cholera, malaria, typhoid fever, eye problems and cough.

When asked about what caused the erratic water supply in Chazanga compound, the results from the research revealed that most of the respondents said having a few tanks caused erratic water supply followed by load shading and few boreholes then, few communal taps. The rest of the respondents said the high demand for water coupled with a growing population, poor water management from suppliers, leakages in water distribution pipes, and small water distribution pipes. The minority of the respondents said the land was too high, hence no water due to low pressure. Others said water was costly and there was negligence by government. On the other hand, only 1 percent of the respondents did not have any knowledge of what caused the erratic water supply in the compound.

The World Bank Report on upgrading of lowincome urban settlements in Lusaka put it clear that water supply from available boreholes was inadequate due to the high population growth that had exceeded the projected demand for water in the peri-urban compounds of Lusaka. However, the study revealed that the number of available boreholes was not statistically related to the erratic water supply in Chazanga compound. All the respondents who had experienced erratic water supply strongly disagreed that the number of boreholes contributed to the erratic water supply. Therefore, the hypothesis that the number of boreholes was not related to the amount of water supplied to the compound holds.

The respondents were further asked if the daily yield from boreholes affected the amount of water supplied to the compound. The study showed that there was no statistical relationship between the daily water yield from boreholes and the erratic supply of water. The hypothesis that the daily yield of water does not significantly affect the amount of water supplied to people also holds.

According to Nyambe and Feilberg [9] the challenges faced in provision of water were high levels of production cost, vandalism of infrastructure and run-down water distribution pipes. For most of the utility water companies in Zambia, there was a reliance on infrastructure that is 30 years old on average. Whereas water conservation was paramount when systems were new, over the years much of this infrastructure deteriorated due to untimely and lack of maintenance. The study showed that leakages from water distribution pipes were significantly related to the erratic supply of water. Based on the findings, the hypothesis that leakages from water distribution pipes do not affect the amount of water supplied was rejected.

Additionally, the study showed that the size of the water reservoirs and the erratic water supply to the compound were not statistically significant. Hence the hypothesis that size of the water reservoir does not significantly affect the erratic supply of water holds.

Finally, when asked on what should be done to improve the supply of water to the compound, respondents gave various recommendations which include; Sink more boreholes, repair the leakages in the distribution pipes, erect more water tanks, fit bigger distribution pipes, construct more communal taps, find an alternative source of power for the water tank and improve the management of water supply by the water suppliers.

In summary the water problems faced by the people in Chazanga compound were extensive and might have adverse effects on the wellbeing of the population in this area. There was, therefore, need for immediate improvements in the water supply to the compound.

The areas that require further research in future are the cost effectiveness of running communal taps against individual household taps; the quality of water in Chazanga compound 
in relation to the waterborne diseases reported at Chazanga clinic; people's attitude towards protecting the water infrastructure from vandalism; impact of effective management by water utility companies in customer satisfaction; and factor hindering full compliance in cost sharing by households in water supply service provision.

\section{Conclusion}

The study was conducted to establish factors contributing to erratic water supply in peri-urban areas, a case study of Chazanga compound of Lusaka district. The study looked at the aspects of available number of water sources, daily water yield, state of repair of water distribution pipes and the size of the water reservoir. The major problem was the erratic water supply in Chazanga compound.

To achieve this, a questionnaire was used to generate data. This was administered to 397 households who were randomly selected. The generated data was later analyzed using the Statistical Package for the Social Sciences (SPSS) for association of factors and the outcomes.

\section{References}

[1] United Nations (2012) Millennium Development Goals Report.

[2] Aster. N (2013) The Problems and Solutions to Safe Water in Africa: United Kingdom.

[3] United Nations (1992) International Conference on Water and the Environment. Dublin, Ireland.

[4] FAO (2013) Zambia UN-Water Country Brief. Zambia.

[5] Howard G and Bartram J (2003) Domestic Water Quantity, Service Level and Health: Geneva. WHO.

[6] MSF (2010) Lusaka's annual cholera disaster: Practical steps for a more effective response. Lusaka. [7] Rukunga G.K (2001) Environmental Health for East Africa. Nairobi: African Medical and Research Foundation.

[8] Lusaka DHMT (2012) Environmental Health Report on Typhoid outbreak in Mtendere east. Lusaka: HMIS.

[9] Nyambe. I and Feilberg. M. (2010). Zambia National Water Resources Report for WWDR3. Ministry of Energy and Water Development. Lusaka. [10]ECZ. (2008) Zambia Environmental Outlook Report 3. Environmental Council of Zambia. Lusaka.
The results of this study revealed interesting issues on the supply of water in Chazanga compound. The problem of erratic water supply was real, and the research revealed other factors other than those in the conceptual framework. Among the other factors were poor management by the water supplier, high demand due to population growth and high cost of water. This erratic water supply in the Chazanga made resident resort to drawing water from unsafe water sources such as shallow wells resulting increase in diarrhea cases reported at Chazanga clinic.

The study results also revealed that to avert the erratic water supply, Chazanga water trust will need to repair all leaking water distribution pipes, sink more boreholes, and erect a bigger water reservoir. The other recommendations were to fit bigger distribution pipes, construct more communal taps, find an alternative source of power for the water tank and improve the management of water supply by the water suppliers.

[11] Mulenga M and Gordon M (2011) Report on ground water self-supply in peri urban settlements of Zambia. Lusaka.

[12]Deming. D (2002) Introduction to Hydrogeology. New York: McGraw-Hill Companies Inc.

[13] Insel P.M and Roth W. T (2001) Core Concepts in Health $\left(9^{\text {th }} E d\right)$. USA: McGraw-Hill Companies Inc.

[14]NWASCO (2005) Urban and Peri-urban Water Supply and Sanitation Sector Report. Lusaka: NWASCO.

[15]Lusaka District Health Management Team (2004) Cholera control guidelines. Lusaka: JICA

[16] Schaefer W (1992) Public Health Engineering. Lusaka, Zambia: UNZA.

[17] World Bank (2002) Report on Upgrading of Low-Income Urban Settlements in Lusaka. Lusaka: World Bank.

[18] Davies M.L and Masten S.J (2004) Principles of Environmental Engineering and Science. New York: McGraw-Hill Companies Inc.

[19] Gleick P.H (1996) Basic water requirements for human activities: meeting basic needs. Vol 21, No. 2: 
Oakland. Pacific Institute for studies in Development, Environment and security.

[20] Kauffmann C (2007) Access to Drinking Water and Sanitation in Africa; policy insight No. 41: Paris.

[21] Muwanei F.W (2007) Research paper on Factors that contribute to inadequate and unsatisfactory storage, collection and disposal of solid waste in Mtendere squatter settlement peri urban in Lusaka. Lusaka. 